\title{
NGHIÊN CỨU CÁC BIẾN CHỨNG SAU PHẪU THUẬT VÀ CÁC YẾU Tố LIÊN QUAN ĐẾN KẾT QUẢ PHẪU THUẬT KÉN KHÍ PHỔI
}

\author{
Châu Phú Thi , Lê Nũ Hòa Hiệp ${ }^{* *}$, Nguyễn Văn Khôi ${ }^{*}$
}

\section{TÓM TẮT}

Có 103 trường hợp được điều trị ngoại khoa xử trí kén khí phổi, trong đó có 67 trường hợp kén khí đơn thuần và 36 trường hợp kén khí kèm khí phế thũng. Biến chứng sau phẫu thuật bao gồm: Dò khí kéo dài có 30 trường hợp (29,1\%), 9 trường hợp $(8,7 \%)$ có tình trạng tràn khí dưới da, xẹp phổi (2 trường hợp chiếm 1,9\%), sốt (2 trường hợp chiếm $1,9 \%)$, chảy máu thành ngực (2 trường hợp chiếm 1,9\%), nhiễm trùng (2 trường hợp chiếm $1,9 \%$ ). Những yếu tố liên quan đến các kết quả thành công trong phẫu thuật bao gồm: tuổi, nhóm bệnh kén khí, tiền sử bệnh, các biểu hiện lâm sàng, điểm khó thở theo thang điểm mMRC, phương pháp phẫu thuật.

Tù khóa: bệnh kén khí phổi, khí phế thũng, biến chứng sau phẫu thuật

\section{SUMMARY}

There were 103 patients in our study, 67 cases group bullous without emphysema and 36 cases group bullous with emphysema. Postoperation complications include: prolong airleak cases were $29,1 \%$; subcutaneous emphysema cases were $8,7 \%$; actelectasis were $1,9 \%$; wound infection were $1,9 \%$. Relevant factors to result of surgery bullous lung disease include : age, group bullous, medical history, clinical symptoms, point scale according mMRC, surgical approach.

Key words: bullous disease of the lung, emphysema, postoperation complications

\section{I. ĐẠTT VẤN ĐỀ}

Bệnh lý kén khí phổi thường biểu hiện trên lâm sàng với các dạng: kén khí hay bóng khí (bulla), bóng khí nhỏ (bleb), và nang khí hoặc túi khí (cyst) [1],[2],[3],[5],[11]

Bệnh kén khí phổi ảnh hưởng nhiều đến sức khoẻ và đời sống của người bệnh do sự phát triển kích thước kén khí phổi làm chèn ép những phần phổi bình thường. Hoặc do có tình trạng hủy hoại nhu mô phổi, trong những kén khí xuất phát tử những bệnh phổi mạn tính.

Điều trị ngoại khoa cho bệnh lý kén khí phổi dựa vào việc chuẩn bị người bệnh trước phẫu thuật, cách phẫu thuật, chăm sóc và điều trị người bệnh sau phẫu thuật. Đánh giá kết quả phẫu thuật xử trí kén khí phổi phụ thuộc nhiều yếu tố như việc cải thiện các biểu hiện lâm sàng, biến chứng sau phẫu thuật, và các yếu tố liên quan khác trong từng loại bệnh kén khí [4],[7],[10]

Vì vậy, chúng tôi tiến hành nghiên cứu về các biến chứng và các yếu tố liên quan khác đến kết quả phẫu thuật xử trí kén khí phổi với các mục tiêu

1. Nghiên cứu các biến chứng sau phẫu thuật xử trí kén khí phổi

2. Đánh giá các yếu tố liên quan đến kết quả phẫu thuật.

\section{PHƯƠNG PHÁP NGHIÊN CÚU}

2.1. Thiết kế nghiên cứu:

Nghiên cứu mô tả tiến cứu

2.2. Thời gian, địa điểm:

Nghiên cứu tiến hành từ tháng $1 / 2012$ đến 1/2014 tại khoa ngoại Lồng Ngực bệnh viện Chợ Rẫy

\subsection{Tiêu chuẩn chọn bệnh:}

Các trường hợp được chẩn đoán kén khí phổi và được phẫu thuật.

\subsection{Tiêu chuẩn loại trừ}

- Những trường hợp được chẩn đoán kén khí

* Bệnh viện Chọ Rẫy Thành phố HCM

** Bộ môn Ngoại Lồng Ngực Tim Mạch ĐHYD TP HCM Nguoòi chịu trách nhiệm khoa học: PGS.TS Lê Nũ Thị Hòa Hiẹpp Ngày nhận bài:10/02/2017 - Ngày Cho Phép Đăng: 10/03/2017 Phản Biện Khoa học: PGS.TS. Đặng Ngọc Hùng GS.TS. Lê Ngọc Thành 
phổi nhưng có những yếu tố chống chỉ định

- Những trường hợp kén khí phổi phát hiện khi phẫu thuật các bệnh lý khác như ung thư phổi, u nấm phổi...

\section{KẾT QUẢ}

Trong thời gian nghiên cứu tiến hành tại kèm khí phế thũng.

Bảng 3.1: Đặc điểm tuổi, giới, tiền sử nhóm nghiên cứu

\begin{tabular}{llll}
\hline Đặc điểm & $\begin{array}{l}\text { Kén khí đơn } \\
\text { thuần } \\
(\mathbf{n = 6 7 )}\end{array}$ & $\begin{array}{l}\text { Kén khí kèm } \\
\text { KPT } \\
(\mathbf{n = 3 6})\end{array}$ & $\begin{array}{l}\text { Cả 2 nhóm } \\
(\mathbf{n = 1 0 3 )}\end{array}$ \\
\hline Nam & $\begin{array}{l}54(80,6 \%) \\
\text { Nữ }\end{array}$ & $\begin{array}{l}32(88,9 \%) \\
4(11,1 \%)\end{array}$ & $\begin{array}{l}86(83,5 \%) \\
17(16,5 \%)\end{array}$ \\
\hline Tuổi trung bình & $38,3 \pm 16,3$ & $57,1 \pm 10,9$ & $44,8 \pm 17,2$ \\
\hline Tiền sử bệnh & & & \\
COPD & $0(0,0 \%)$ & $26(72,2 \%)$ & $26(25,2 \%)$ \\
Tràn khí màng phổi & $18(26,9 \%)$ & $11(30,6 \%)$ & $29(28,2 \%)$ \\
Lao phổi & $1(1,5 \%)$ & $5(13,9 \%)$ & $6(5,8 \%)$ \\
Hút thuốc lá & $32(47,8 \%)$ & $28(77,8 \%)$ & $60(58,3 \%)$ \\
Bệnh tim mạch & $2(3,0 \%)$ & $2(5,6 \%)$ & $4(3,9 \%)$ \\
Bệnh tiểu đường & $0(0,0 \%)$ & $2(5,6 \%)$ & $2(1,9 \%)$ \\
\hline
\end{tabular}

Bảng 3.2: Đặc điểm lâm sàng

\begin{tabular}{llll}
\hline Đặc điểm & $\begin{array}{l}\text { Kén khí đơn } \\
\text { thuần } \\
(\mathbf{n = 6 7})\end{array}$ & $\begin{array}{l}\text { Kén khí kèm KPT } \\
(\mathbf{n = 3 6})\end{array}$ & $\begin{array}{l}\text { Cả 2 nhóm } \\
(\mathbf{n = 1 0 3 )}\end{array}$ \\
\hline Ho ra máu & $1(1,5 \%)$ & $0(0,0 \%)$ & $1(1,0 \%)$ \\
Đau ngực & $64(95,6 \%)$ & $34(94,4 \%)$ & $98(95,1 \%)$ \\
Khó thở & $56(83,5 \%)$ & $36(100 \%)$ & $92(89,3 \%)$ \\
Ho đàm & $7(10,5 \%)$ & $28(77,8 \%)$ & $35(34,0 \%)$ \\
Đang có DL MP & $41(61,2 \%)$ & $26(72,2 \%)$ & $67(65,0 \%)$ \\
\hline$m M R C$ 0 điểm & $11(16,5 \%)$ & $0(0,0 \%)$ & $11(9,7 \%)$ \\
$m M R C$ 1 điểm & $48(71,6 \%)$ & $19(52,8 \%)$ & $67(65,0 \%)$ \\
$m M R C 2$ điểm & $8(11,9 \%)$ & $17(47,2 \%)$ & $25(24,3 \%)$ \\
\hline
\end{tabular}


Bảng 3.3: Phuoong pháp phẫu thuật

\begin{tabular}{lccc}
\hline Đặc điểm & $\begin{array}{l}\text { Kén khí đơn thuần } \\
(\mathbf{n = 6 7 )}\end{array}$ & $\begin{array}{l}\text { Kén khí kèm KPT } \\
(\mathbf{n = 3 6 )}\end{array}$ & $\begin{array}{l}\text { Cả 2 nhóm } \\
(\mathbf{n = 1 0 3 )}\end{array}$ \\
\hline Phẫu thuật mở & $19(28,4 \%)$ & $22(61,1 \%)$ & $41(39,8 \%)$ \\
Cắt kén & $17(25,4 \%)$ & $22(61,1 \%)$ & $39(37,9 \%)$ \\
Cắt thuỳ & $2(3,0 \%)$ & $0(0,0 \%)$ & $2(1,9 \%)$ \\
\hline Phẫu thuật nội soi & $48(71,6 \%)$ & $14(38,9 \%)$ & $62(60,2 \%)$ \\
Cắt kén & $47(70,1 \%)$ & $14(38,9 \%)$ & $61(59,2 \%)$ \\
Cắt thuỳ & $1(1,5 \%)$ & $0(0,0 \%)$ & $1(1,0 \%)$ \\
\hline
\end{tabular}

Bảng 3.4: Biến chưng phẫu thuật

\begin{tabular}{llll}
\hline Đặc điểm & $\begin{array}{l}\text { Kén khí đơn thuần } \\
(\mathbf{n = 6 7})\end{array}$ & $\begin{array}{l}\text { Kén khí kèm } \\
\text { KPT }(\mathbf{n = 3 6 )}\end{array}$ & $\begin{array}{l}\text { Cả 2 nhóm } \\
(\mathbf{n = 1 0 3})\end{array}$ \\
\hline Rò khí kéo dài & $8(13,4 \%)$ & $22(61,1 \%)$ & $30(29,1 \%)$ \\
Xẹp phổi & $1(1,5 \%)$ & $1(2,8 \%)$ & $2(1,9 \%)$ \\
Sốt & $2(3,0 \%)$ & $0(0,0 \%)$ & $2(1,9 \%)$ \\
Tràn khí dưới da & $1(1,5 \%)$ & $8(22,2 \%)$ & $9(8,7 \%)$ \\
Chảy máu thành ngực & $1(1,5 \%)$ & $1(2,8 \%)$ & $2(1,9 \%)$ \\
Nhiễm trùng & $1(1,5 \%)$ & $1(2,8 \%)$ & $2(1,9 \%)$ \\
Mổ lại cắt kén khí & $1(1,5 \%)$ & $1(2,8 \%)$ & $2(1,9 \%)$
\end{tabular}

Bảng 3.5: Kết quả phẫu thuật

\begin{tabular}{|c|c|c|c|}
\hline Đặc điểm & $\begin{array}{l}\text { Kén khí đơn thuần } \\
(n=67)\end{array}$ & $\begin{array}{l}\text { Kén khí kèm KPT } \\
(n=36)\end{array}$ & $\begin{array}{lrl}\text { Cả } & 2 & \text { nhóm } \\
(n=103) & \end{array}$ \\
\hline Tốt & $54(80,6 \%)$ & $12(33,3 \%)$ & $66(64,1 \%)$ \\
\hline Chưa tốt & $13(19,4 \%)$ & $24(66,7 \%)$ & $37(35,9 \%)$ \\
\hline Tử vong & $0(0,0 \%)$ & $0(0,0 \%)$ & $0(0,0 \%)$ \\
\hline
\end{tabular}

Bảng 3.6: Phân tích đơn biến các yếu tố liên quan đến kết quả phẫu thuật

\begin{tabular}{llllll}
\hline Đặc điểm & $\begin{array}{l}\text { Tốt } \\
(\mathbf{n = 6 6 )}\end{array}$ & $\begin{array}{l}\text { Chưa tốt } \\
(\mathbf{n = 3 7 )}\end{array}$ & OR & $\begin{array}{l}\text { Khoảng tin } \\
\text { cậy 95\% }\end{array}$ & $\begin{array}{l}\text { Giá trị } \\
\mathbf{p}\end{array}$ \\
\hline $\begin{array}{l}\text { Tuổi }(\text { năm) } \\
\text { Giới tính }\end{array}$ & $\mathbf{4 1 , 8} \pm \mathbf{1 6 , 8}$ & $\mathbf{5 0 , 2} \pm \mathbf{1 6 , 6}$ & $\mathbf{1 , 0 3}$ & $\mathbf{1 , 0 0 - 1 , 0 6}$ & $\mathbf{0 , 0 1 9}$ \\
Nữ & $12(18,2 \%)$ & $5(13,5 \%)$ & 1 & - & - \\
Nam & $54(81,8 \%)$ & $32(86,5 \%)$ & 1,42 & $0,46-4,41$ & 0,542 \\
\hline Nhóm bệnh & & & & & \\
Kén khí ĐT & $54(81,8 \%)$ & $13(35,1 \%)$ & 1 & - & - \\
KK kèm KPT & $\mathbf{1 2}(\mathbf{1 8 , 2 \%})$ & $\mathbf{2 4}(\mathbf{6 4 , 9 \% )}$ & $\mathbf{8 , 3 1}$ & $\mathbf{3 , 3 1 - \mathbf { 2 0 , 8 5 }}$ & $<\mathbf{0 , 0 0 1}$ \\
\hline
\end{tabular}


Tiền sü

\begin{tabular}{|c|c|c|c|c|c|}
\hline COPD & $5(7,6 \%)$ & $21(56,8 \%)$ & 16,01 & $5,22-49,07$ & $<0,001$ \\
\hline TKMP & $14(21,2 \%)$ & $15(40,5 \%)$ & 2,53 & $1,05-6,12$ & $\mathbf{0 , 0 3 9}$ \\
\hline Lao phổi & $0(0,0 \%)$ & $6(16,2 \%)$ & 16,64 & 2,31 - Inf & 0,003 \\
\hline Hút thuốc lá & $32(48,5 \%)$ & $28(75,7 \%)$ & 3,31 & $\mathbf{1 , 3 5}-\mathbf{8 , 0 7}$ & 0,009 \\
\hline TS tim mạch & $3(4,6 \%)$ & $0(0,0 \%)$ & 0,45 & $0-4,31$ & 0,518 \\
\hline Tiểu đường & $1(1,5 \%)$ & $1(2,7 \%)$ & 1,81 & $0,11-29,74$ & 0,679 \\
\hline \multicolumn{6}{|c|}{ Triệu chúng lâm sàng } \\
\hline Ho ra máu & $1(1,5 \%)$ & $0(0,0 \%)$ & 1,78 & $0-69,57$ & 1 \\
\hline Đau ngực & $62(93,9 \%)$ & $36(97,3 \%)$ & 2,32 & $0,25-21,59$ & 0,459 \\
\hline Ho đàm & $11(16,7 \%)$ & $24(64,9 \%)$ & $\mathbf{9 , 2 3}$ & $3,62-23,52$ & $<0,001$ \\
\hline \multicolumn{6}{|c|}{ Múc độ khó thơ theo mMRC } \\
\hline 0 điểm & $10(15,2 \%)$ & $1(2,7 \%)$ & 1,78 & $0-69,57$ & 1 \\
\hline 1 điểm & $44(66,7 \%)$ & $23(62,2 \%)$ & 2,56 & $1,20-5,49$ & 0,015 \\
\hline 2 điểm & $12(18,2 \%)$ & $13(35,1 \%)$ & 6,57 & $\mathbf{1 , 4 3}-\mathbf{3 0 , 0 9}$ & 0,015 \\
\hline \multicolumn{6}{|c|}{ Phuoong pháp phẫu thuật } \\
\hline PT nội soi & $50(75,8 \%)$ & $12(32,4 \%)$ & 1 & - & - \\
\hline PT mỏ̉ & $16(24,2 \%)$ & $25(67,6 \%)$ & 6,51 & $2,68-15,84$ & $<0,001$ \\
\hline \multicolumn{6}{|c|}{ Phuoong pháp xủ trí kén } \\
\hline Cắt kén khí & $63(95,5 \%)$ & $37(100,0 \%)$ & 1 & - & - \\
\hline Cắt thuỳ & $3(4,6 \%)$ & $0(0,0 \%)$ & 0,45 & $0-4,31$ & 0,518 \\
\hline
\end{tabular}

\section{BÀN LUẬN}

\subsection{Kết quả phẫu thuật (Bảng 3.5)}

Chúng tôi đã phẫu thuật cho 103 trường hợp trong nghiên cứu, kết quả phẫu thuật đạt được:

- Kết quả tốt có 66 trường hợp $(64,1 \%)$ cho cả 2 nhóm nghiên cứu, trong đó nhóm kén khí đơn thuần có 54 trường hợp $(80,6 \%)$, nhóm kén khí phế thũng có 12 trường hợp $(33,3 \%)$. Đây là những trường hợp người người bệnh sau khi phẫu thuật xử trí kén khí có cải thiện triệu chứng lâm sàng, không có biến chứng hậu phẫu.

- Kết quả chưa tốt có 37 trường hợp $(35,9 \%)$ cho cả 2 nhóm nghiên cứu, trong đó nhóm kén khí đơn thuần có 13 trường hợp $(19,4 \%)$, nhóm kén khí phế thũng có 24 trường hợp (66,7\%). Đây là những trường hợp có cải thiện lâm sàng, cận lâm sàng, nhưng có biến chứng sau phẫu thuật.

Trong đó, có 2 trường hợp, nhóm kén khí đơn thuần có 1 trường hợp, nhóm kén khí phế thũng 1 trường hợp cần phẫu thuật lại để giải quyết biến chứng. Hai trường hợp này là 2 trường hợp dò khí kéo dài do còn kén khí chưa cắt hết.

Tử vong : không có trường hợp nào tử vong sau khi phẫu thuật. 
So sánh với các tác giả khác, ta có:

\begin{tabular}{|l|l|l|l|}
\hline & Tốt & Chưa tốt & Tử vong \\
\hline Antonio Palla (n=41) [12] & $85,4 \%$ & $7,3 \%$ & $7,3 \%$ \\
\hline Paul H. Schipper (n= 43) [13] & $79 \%$ & $18,6 \%$ & $2,4 \%$ \\
\hline Yasir Ahmad Lone (n=54) [10] & $72,3 \%$ & $24 \%$ & $3,7 \%$ \\
\hline Châu Phú Thi (n=103) & $64,1 \%$ & $35,9 \%$ & $0 \%$ \\
\hline
\end{tabular}

Trong thời gian hậu phẫu chúng tôi thường xuyên tiến hành thăm khám lâm sàng, theo dõi bình dẫn lưu màng phổi, chụp X quang phổi để có thể phát hiện sớm các biến chứng hậu phẫu, giải quyết tốt các biến chứng hậu phẫu sẽ làm giảm thời gian nằm viện sau mổ cho người bệnh.

\subsection{Các biến chứng được ghi nhận trong}

\section{(bảng 3.4)}

- Dò khí kéo dài có 30 trường hợp $(29,1 \%)$, trong đó nhóm kén khí đơn thuần có 8 trường hợp $(13,4 \%)$ ít hơn so với nhóm kén khí kèm khí phế thũng (21 trường hợp chiếm 61,1\%). Có nhiều yếu tố gây nên tình trạng dò khí kéo dài ở hậu phẫu như phổi dày dính nhiều cần bóc tách nhiều trong lúc phẫu thuật, tình trạng phổi có khí phế thũng lan tỏa ở nhiều thùy cũng là nguyên nhân gây dò khí màng phổi kéo dài.

- Biến chứng có tỉ lệ cao tiếp theo là tràn khí dưới da, trong nghiên cứu 9 trường hợp $(8,7 \%)$ có tình trạng tràn khí dưới da. Nhóm kén khí đơn thuần có 1 trường hợp $(1,5 \%)$, nhóm kén khí kèm khí phế thũng ( 8 trường hợp chiếm $22,2 \%$ ).

- Ngoài ra trong nghiên cứu chúng tôi, còn gặp các biến chứng khác như xẹp phổi (2 trường hợp chiếm 1,9\%), sốt (2 trường hợp chiếm 1,9\%), chảy máu thành ngực ( 2 trường hợp chiếm 1,9\%), nhiễm trùng (2 trường hợp chiếm 1,9\%).

- Mổ cắt lại kén khí có 2 trường hợp, 1 trường hợp trong nhóm kén khí đơn thuần được phẫu thuật nội soi và sau mổ còn sót kén khí gây tình trạng dò khí kéo dài không lành nên phải phẫu thuật lại. Còn 1 trường hợp trong nhóm kén khí kèm khí phế thủng được phẫu thuật mở ngực xử trí kén khí nhưng tình trạng khí phế thủng không lành tốt gây dò khí kéo dài nên cũng phải mổ lại để khâu lại phần phổi không lành.

So sánh với các tác giả khác cũng có những biến chứng tương tự khi phẫu thuật xử trí kén khí phổi:

Tác giả Pradheep Krishnamohen, có 30,1\% biến chứng rò khí dai dẳng, 4,7\% biến chứng chảy máu vết mổ, 12,6\% biến chứng viêm phổi [9].

Tác giả Yasir Ahmad Lone trong nghiên cứu có $25,9 \%$ biến chứng rò khí dai dẳng, có $3,7 \%$ có tình trạng nhiễm trùng khoang màng phổi. [10]

Tác giả Gunnarsson, có $75 \%$ dò khí kéo dài và $17 \%$ viêm phổi sau khi phẫu thuật [6].

\subsection{Biến chứng so với phương pháp mổ.}

Phẫu thuật nội soi có biến chứng sau mổ chiếm 19,4\% trường hợp, ít hơn phẫu thuật mở ngực có biến chứng sau mổ là $61 \%$.

- Phẫu thuật nội soi cho nhóm kén khí đơn thuần có $10,4 \%$ trường hợp có biến chứng, nhóm kén khí kèm khí phế thũng có $50 \%$ trường hợp có biến chứng.

- Phẫu thuật mở ngực cho nhóm kén khí đơn thuần có $42,1 \%$ trường hợp có biến chứng, nhóm kén khí kèm khí phế thũng có 77,3\% trường hợp có biến chứng.

Ta thấy, nhóm kén khí kèm khí phế thũng có biến chứng phẫu thuật cao hơn nhóm kén khí đơn thuần trong cả 2 phương pháp phẫu thuật.

Nhóm kén khí đơn thuần ít biến chứng sau phẫu thuật nội soi hơn so với phẫu thuật mở ngực. 
Kết quả phẫu thuật đạt kết quả tốt hay không có thể phụ thuộc vào một hoặc nhiều yếu tố bệnh lý của người bệnh, theo nhiều nghiên cứu khác trên thế giới, như của tác giả Pradheep Krishnamohen, Andrea Imperatori...đã đưa ra nhiều yếu tố liên quan đến khả năng xuất hiện biến chứng sau phẫu thuật ảnh hưởng đến kết quả phẫu thuật. [8],[9]

Những yếu tố được đưa vào phân tích để tìm các mối liên quan dẫn đến các kết quả thành công trong điều trị ngoại khoa cho hai nhóm bệnh kén khí bao gồm: tuổi, nhóm bệnh kén khí, tiền sử bệnh, các biểu hiện lâm sàng, điểm khó thở theo thang điểm mMRC, phương pháp phẫu thuật nội soi hay mở ngực, phương pháp xử trí cắt kén khí hay cắt thùy phổi.

Chúng tôi sử dụng phân tích hồi quy đơn biến và đa biến để đánh giá sự liên quan của các yếu tố này đến kết quả phẫu thuật.

Sau khi phân tích hồi quy đơn biến, chúng tôi thấy :

- Phẫu thuật cho nhóm người bệnh có tuổi cao hơn sẽ ảnh hưởng không tốt gấp 1,03 lần nhóm người bệnh trẻ tuổi, khác biệt này có ý nghĩa thống kê với $\mathrm{p}<0,05$.
- Phẫu thuật cho nhóm bệnh kén khí kèm tình trạng khí phế thũng có khả năng không tốt gấp 8,31 lần so với nhóm kén khí đơn thuần, khác biệt này cũng có ý nghĩa thống kê với $\mathrm{p}<0,05$.

- Đối với những người bệnh có tiền sử bệnh thuốc lá, bệnh phổi mạn tính cũng tăng khả năng không tốt khi phẫu thuật :

- Có tiền sử COPD : tăng không tốt gấp16,01 lần

- Tiền sử tràn khí màng phổi : tăng không tốt gấp 2,53 lần

- Lao phổi: tăng không tốt gấp 16,64 lần

- Hút thuốc lá: tăng không tốt gấp 3,31 lần.

Sự khác biệt này có ý nghĩa thống kê trong phân tích hồi quy đơn biến với $\mathrm{p}<0,05$.

- Những người bệnh có điểm khó thở mMRC trên lâm sàng 1 hoặc 2 điểm có khả năng kết quả không tốt gấp 2,56 hoặc 6,57 lần, sự khác biệt này có ý nghĩa thống kê trong phân tích hồi quy đơn biến với $\mathrm{p}<0,05$.

So sánh phương pháp phẫu thuật, phẫu thuật mổ mở sẽ cho kết quả chưa tốt gấp 6,51 lần so với phẫu thuật nội soi, sự khác biệt này có ý nghĩa thống kê trong phân tích hồi quy đơn biến với $\mathrm{p}<0,05$.

So sánh với các nghiên cứu khác, ta thấy các tác giả cũng nghiên cứu những yếu tố liên quan tương tự nghiên cứu chúng tôi, nhưng có những kết quả khác tùy theo số liệu nghiên cứu như :

\begin{tabular}{|l|l|l|l|l|l|l|}
\hline \multirow{2}{*}{} & \multicolumn{3}{|l|}{ Pradheep } & \multicolumn{2}{l|}{ Andrea Imperatori } & \multicolumn{2}{l|}{ C.P Thi } \\
\cline { 2 - 7 } & OR & $\mathrm{p}$ & OR & $\mathrm{p}$ & $\mathrm{OR}$ & $\mathrm{p}$ \\
\hline Tuối cao & 2,7 & 0,07 & 1,01 & 0,82 & $\mathbf{1 , 0 3}$ & $\mathbf{0 , 0 1 9}$ \\
\hline Giới tính (nam) & 1,6 & 0,46 & $\mathbf{1 , 2 2}$ & $\mathbf{0 , 0 2 6}$ & 1,42 & 0,542 \\
\hline TS hút thuốc & 7,4 & 0,07 & 1,13 & 0,868 & $\mathbf{3 , 3 1}$ & $\mathbf{0 , 0 0 9}$ \\
\hline TS TKMP & & & $\mathbf{4 , 7 6}$ & $\mathbf{0 , 1 5}$ & $\mathbf{2 , 5 3}$ & $\mathbf{0 , 0 3 9}$ \\
\hline Nhóm có KPT & $\mathbf{7 , 3}$ & $\mathbf{0 , 0 1}$ & & & $\mathbf{8 , 3 1}$ & $<\mathbf{0 , 0 0 1}$ \\
\hline
\end{tabular}

\section{KẾT LUẬN}

Biến chứng sau phẫu thuật xử trí kén khí phổi thường gặp là dò khí màng phổi dai dẳng, và tràn khí dưới da, trong đó gặp nhiều trong nhóm bệnh kén khí phổi kèm khí phế thũng.

Người bệnh kén khí kèm khí phế thũng có 
tuổi cao, có các tiền sử bệnh phổi như COPD, lao phổi hay có tiền sử hút thuốc lá khi phẫu thuật có nhiều khả năng cho kết quả phẫu thuật không tốt.

\section{TÀI LIỆU THAM KHẢO}

1. Nguyễn Công Minh (2010), "Đánh giá kết quả điều trị ngoại khoa bệnh kén khí phổi tại bệnh viện Chợ Rẫy trong 10 năm (19992008)". Y Học TP. Hồ Chí Minh, 14 (2).

2. Agrawal G., Gupta D. (2010), "Bronchiolar and bullous lung disease". Textbook of Pulmonary and Critical Care Medicine, 2 (91), pp. 1132-8.

3. Angelica F., Francisco F. (2015), "Multiple Cystic Lung Disease". European Respiratory Journal, 24 (552-64).

4. Chunghtai T., Perron E. (2009), "Bullous and bleb diseases of the lung". General Thoracic Surgery, pp. 1077-98.

5. Fernando J. Martinez (2015), "Bullous Disease of the Lung", Fishman's Pulmonary Diseases and Disorders". chapter 52, pp. 787-99.

6. Gunnarsson S.I. (2012), "Incidence and outcomes of surgical resection for giant pulmonary bullae-a population-based study". Scandinavian Journal of surgery, 101, pp. 166-9.
7. Haciîbrahîmoğlu G. (2002), "The Comparison of Videothoracoscopy and Thoracotomy in The Treatment of Bullous Lung Disease". Eurasian Journal of Pulmonary, 4 (1), pp. 23-5.

8. Imperatori A., Rotolo N. (2015), "Risk factors for postoperative recurrence of spontaneous pneumothorax treated by video-assisted thoracoscopic surgery". Interact Cardiovacs Thoracic Surgery, 20 (5), pp. 647- 52.

9. Krishnamohen P. (2014), "Bullectomy for Symptomatic or Complicated Giant Lung Bulla". Annals of Thoracic Surgery, 97, pp. 425-31.

10. Lone Y. A. (2012), "Outcome of the Surgical Treatment of Bullous Lung Disease: A Prospective Study". Tanaffos, 11 (2), pp. 27-33.

11. Odev K. (2012), "Imaging Findings of Focal and Multiple Cystic and Cavitary Lung Lesions". European Journal of General Medicine, 9 (1), pp. 3-14.

12. Palla A. (2005), "Elective Surgery for Giant Bullous Emphysema: a 5-years clinical and functional follow-up". Chest, 128 (4), pp. 2043-50.

13. Schipper P. H. (2004), "Outcomes after resection of giant emphysematous bullae". Annals of Thoracic Surgery, 78, pp. 976-82. 